\title{
Simulations of black carbon over the Indian region: improvements and implications of diurnality in emissions
}

\author{
Gaurav Govardhan ${ }^{1,2}$, Sreedharan Krishnakumari Satheesh ${ }^{1,2}$, Krishnaswamy Krishna Moorthy ${ }^{1}$, and \\ Ravi Nanjundiah ${ }^{1,2,3}$ \\ ${ }^{1}$ Centre for Atmospheric and Oceanic Sciences, Indian Institute of Science, Bangalore, India \\ ${ }^{2}$ Divecha Centre for Climate Change, Indian Institute of Science, Bangalore, India \\ ${ }^{3}$ Indian Institute of Tropical Meteorology, Pune, India
}

Correspondence: Gaurav Govardhan (govardhan.gaurav@gmail.com)

Received: 15 February 2019 - Discussion started: 26 February 2019

Revised: 24 May 2019 - Accepted: 2 June 2019 - Published: 25 June 2019

\begin{abstract}
With a view to improving the performance of WRF-Chem over the Indian region in simulating BC (black carbon) mass concentrations as well as its short-term variations, especially on a diurnal scale, a region-specific diurnal variation scheme has been introduced in the model emissions and the performance of the modified simulations has been evaluated against high-resolution measurements carried out over eight ARFI (Aerosol Radiative Forcing over India) network observatories spread across India for distinct seasons: pre-monsoon (represented by May), post-monsoon (represented by October) and winter (represented by December). In addition to an overall improvement in the simulated concentrations and their temporal variations, we have also found that the effects of prescribing diurnally varying emissions on the simulated near-surface concentrations largely depend on the boundary layer turbulence. The effects are perceived quickly (within about 2-3 h) during the evening-early morning hours when the atmospheric boundary layer is shallow and convective mixing is weak, while they are delayed, taking as much as about $5-6 \mathrm{~h}$, during periods when the boundary layer is deep and convective mixing is strong. This information would also serve as an important input for agencies concerned with urban planning and pollution mitigation. Despite these improvements in the near-surface concentrations, the simulated columnar aerosol optical depth (AOD) still remains largely underestimated vis-à-vis the satellite-retrieved products. These modifications will serve as a guideline for further model-improvement initiatives at a regional scale.
\end{abstract}

\section{Introduction}

The potential of aerosols to significantly offset regional climate through scattering and absorption of solar and terrestrial radiation, and modifying cloud properties, is now unequivocally accepted. This includes impacts on the large-scale climate systems such as the monsoons (Chakraborty et al., 2004; Ramanathan et al., 2005; Lau et al., 2006; Vinoj et al., 2014), formation and evolution of large-scale tropical cyclones (Hazra et al., 2013; Herbener et al., 2014; Wang et al., 2014), and the terrestrial glacial cover (Yasunari et al., 2010; Nair et al., 2013; Lau et al., 2010), apart from the irreparable damage to human health (Davidson et al., 2005; Valavanidis et al., 2008; Shiraiwa et al., 2012). All such aerosolcloud-cryosphere-climate-human interactions are important over the southern Asian region, which is known to be among the hotspots of aerosols. These interactions assume societal importance as the region is home to more than a billion of the human population. Though station-based or space-based measurements help us in enhancing our understanding of such interactions, numerical models are essential to critically analyze the different components of these interactions in isolation as well as predicting future scenarios and helping in policy decisions. However, applications of such models are limited by the associated shortcomings. One of the common problems among many such chemistry transport models is the unrealistic simulations of aerosol loading as well as its temporal variations over the Indian region, as has been pointed out by several recent studies (Reddy et al., 2004; Chin et al., 2009; Ganguly et al., 2009; Goto et al., 2011; Nair et al., 2012; Cherian et al., 2013; Moorthy et al., 2013; 
Pan et al., 2015; Kumar et al., 2015; Feng et al., 2016; Govardhan et al., 2015, 2016). Examining the performance of the RegCM4 model over the southern Asian region, Nair et al. (2012) found that despite near-realistic simulation of aerosol optical depth (AOD) over remote and cleaner oceanic regions, the model significantly underestimates AOD even over the moderately polluted continental belt of the southern Asian region. The study also acknowledged that the boundary layer processes within the RegCM4 model limit its performance in simulating near-surface black carbon (BC) mass concentrations over the region during periods when the vertical dispersion is limited by a shallow boundary layer. Performing an extensive performance evaluation of simulations with in situ measurements, Moorthy et al. (2013) reported that inadequacies in convective boundary layer parameterization and inaccuracies in emission inventories lead largely to the poor performance of GOCART simulations over the Indian region. Carrying out multi-model evaluation, Pan et al. (2015) identified erroneous simulations of relative humidity as one of the major causes, while Govardhan et al. (2015), examining the performance of WRF-Chem over the Indian region, concluded that emissions of $\mathrm{BC}$ and boundary layer parametrization are important in BC-related model underestimations. Continuing it further, Govardhan et al. (2016) quantified the underestimations in BC emissions in five widely used inventories. Thus, the models employed to simulate aerosol loading over the Indian region appear to be impaired by unrealistic emissions of BC. Besides the use of such grossly underestimated emissions, it is also noted that the models used time-invariant emission strength for the anthropogenic pollutants, especially neglecting the diurnal variation that would arise due to time-dependent sources (vehicular traffic or domestic activities, etc.).

With a view to improving the model simulations, especially in simulating their short-term variation, we prescribed a diurnal variation scheme to the emissions employed in the WRF-Chem model and used a spatially uniform adjustment factor to account for the underestimation in BC concentration (as revealed in earlier studies). The effects of such modifications on the simulated near-surface BC mass concentrations (henceforth referred to as NSBC mass concentration) and columnar AOD are examined by comparing them with in situ observations from a network of observatories as well as with space-based measurements. Additionally, the role that diurnality in $\mathrm{BC}$ emissions plays in controlling the simulated near-surface mass concentrations has also been examined. The details are provided in Sects. 2 and 3, the results are discussed in Sect. 4, and the conclusions are given in Sect. 5.

\section{Model details}

The version of the WRF-Chem model used in this study is similar to the one used in our earlier studies as described in Govardhan et al. $(2015,2016)$. The model has been set over the Indian domain $\left(55-97^{\circ} \mathrm{E}, 1-37^{\circ} \mathrm{N}\right)$ and is run for a period of 1 representative month each in the pre-monsoon (May), post-monsoon (October) and winter (December) seasons of the year 2011. The simulation months are so chosen that they capture the distinct temporal features of the aerosol loading over the region, namely the pre-monsoonal maxima, the post-monsoonal build-up (after the washout) and the wintertime secondary maxima as explained in Fig. 1 of Govardhan et al. (2015). The region experiences a minimum in aerosol loading during June through August due to monsoonal wet scavenging. It has been seen in our earlier studies (Govardhan et al., 2015, 2016) that the model simulations show a good comparison with observations when the ambient aerosol loading is less. Thus, keeping in mind such a behavior of the model, we chose to carry out the model simulations and further evaluations only for those seasons which depict relatively higher aerosol burden over the Indian region (i.e., pre-monsoon, post-monsoon and winter). The rest of the model details remain the same as those given in Govardhan et al. (2015) and Govardhan et al. (2016).

\subsection{Modifications of the emission scheme}

The prescribed emissions of $\mathrm{BC}$ over the Indian region that are employed in our previous studies (Govardhan et al., 2015, 2016) have been seen to be unrealistic, though they are on par with the CMIP5 emission database (Govardhan et al., 2016). In this study, the prescribed emissions, in the model, of BC (and other anthropogenic pollutants such as organic carbon (OC), $\mathrm{SO}_{2}, \mathrm{CO}, \mathrm{NO}$ and $\mathrm{NO}_{2}$ ) associated with fossil fuel combustion activities have been modified considering the realistic diurnal variations seen across the Indian mainland (Goyal and Krishna, 1998; Sivacoumar et al., 2001), which is represented in Fig. 1. It depicts two characteristic peaks, one in the morning (between 08:00 and 10:00) and the other in the evening (between 18:00 and 20:00) mostly associated with urban traffic and domestic (cooking) activities. The prescription of a diurnal variation involves multiplying the original emission intensity, which is rather time-invariant, by a diurnally varying factor (which is called the "diurnality factor" (DF)). In doing so, we ensure that the total emissions integrated over a day remain unchanged; only their magnitude is varied as indicated by Fig. 1. However, the spatial distinctiveness of the diurnality factor, which depends on the nature and strength of the region sources, is not considered; rather, it is assumed to follow the same pattern across the entire domain following Goyal and Krishna (1998) and Sivacoumar et al. (2001). Additionally, based on the results of Govardhan et al. (2016) regarding underestimated $\mathrm{BC}$ emissions across India (model bias), we further modify the $\mathrm{BC}$ emissions by multiplying them by a uniform adjustment factor (AF) of 3 , on top of the prescribed diurnal variation.

Upon carrying out the aforementioned modifications in emissions, we have carried out three sets of simulations for 1 representative month of each season: May (pre-monsoon); 


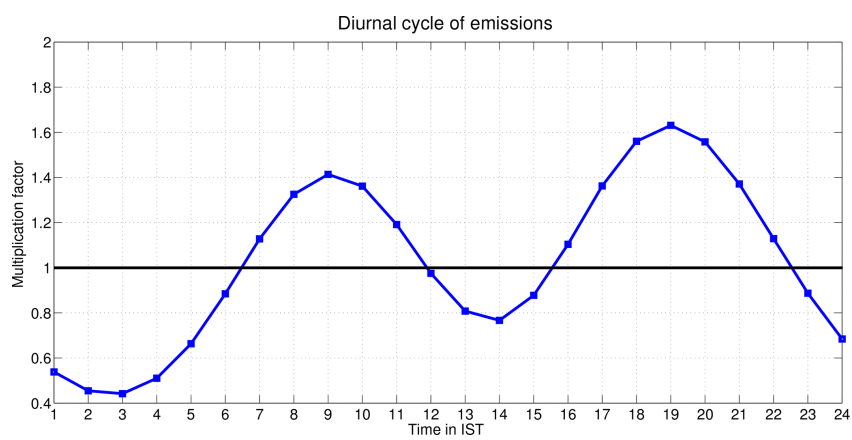

Figure 1. The prescribed diurnal variation to the emissions of $\mathrm{BC}$, OC, sulfate, $\mathrm{SO}_{2}, \mathrm{CO}, \mathrm{NO}$ and $\mathrm{NO}_{2}$ in this study.

October (post-monsoon) and December (winter) for the year 2011. The CTRL simulation configuration does not have the prescription of the diurnal variation and the adjustment factor to the emissions, while the DIEM simulations have only the diurnal variation in the emissions of anthropogenic pollutants prescribed over the CTRL scheme. The DIEM+AF configuration has the prescription of both the diurnality factor (DF) and an adjustment factor of 3 (for bias correction) on the emissions of BC. We next have examined the effects of such modifications in emissions of pollutants in general and $\mathrm{BC}$ in particular on the aerosol loading and its related climatic effects over the Indian region.

\section{Measurement data used}

To evaluate the performance of the model with these modifications on the simulated NSBC mass concentration, we used high-time-resolution measurements of $\mathrm{BC}$ mass concentrations from eight network stations across India for the same periods, where regular BC measurements are being made under the Indian Space Research Organisation's Aerosol Radiative Forcing over India (ARFI) program (Moorthy et al., 2013). The stations chosen are Bangalore (urban-continental, $12.96^{\circ} \mathrm{N}, 77.58^{\circ} \mathrm{E}$ ), Chennai (urban-coastal, $13.08^{\circ} \mathrm{N}, 80.27^{\circ} \mathrm{E}$ ), Hyderabad (urban-continental, $17.37^{\circ} \mathrm{N}, 78.48^{\circ} \mathrm{E}$ ), Trivandrum (semiurban-coastal, $8.37^{\circ} \mathrm{N}, 76.9^{\circ} \mathrm{E}$ ), Anantapur (semi-urbancontinental, $14.68^{\circ} \mathrm{N}, 77.6^{\circ} \mathrm{E}$ ), Varanasi (semi-urban, polluted continental, $25.28^{\circ} \mathrm{N}, 82.97^{\circ} \mathrm{E}$ ), Ranchi (semi-urban, polluted continental, $23.35^{\circ} \mathrm{N}, 85.33^{\circ} \mathrm{E}$ ) and Dibrugarh (semi-urban, remote continental, $27.48^{\circ} \mathrm{N}, 95^{\circ} \mathrm{E}$ ).

\section{Results}

\subsection{Effects of modified emissions on NSBC: model vs. observations}

The simulated NSBC mass concentrations in the CTRL and $\mathrm{DIEM}+\mathrm{AF}$ model configurations are compared with the corresponding measurements, as mentioned above, for the 3 months of simulation (Figs. 2 and 3). The monthly-mean diurnal variation in the measured NSBC mass concentration (black line, Fig. 2) over all the stations, in general, depicts the pronounced bi-modal behavior, with a morning peak occurring around 07:30-08:30 local time, which arises due to the combined effects of (a) enhanced emissions from the domestic and traffic sectors as discussed earlier and (b) a fumigation effect triggered by the increasing thermal convections that breaks the nocturnal capping inversion and brings in particles trapped in the residual layer, as has been discussed in earlier works (Stull, 2012; Nair et al., 2012; Moorthy et al., 2013; Govardhan et al., 2015). Convective mixing strengthens further into the daytime and the atmospheric boundary layer (ABL) deepens, resulting in more vertical dispersion of near-surface $\mathrm{BC}$ and a consequent dilution in the NSBC mass concentration. During evening to the nighttime, the traffic and domestic emissions increase again, while the reduced vertical mixing and shallow nocturnal boundary layer result in the confinement of the particles near the surface, thus contributing to the high $\mathrm{BC}$ concentrations (black line, Fig. 2). The observed reductions in NSBC mass concentration postmidnight (black line, Fig. 2), despite the stable atmospheric boundary layer, are attributed to the reduced nocturnal emissions.

The model in the CTRL configuration (blue line, Fig. 2) fails to simulate the magnitude of the observed NSBC mass concentration, over all the stations, for all times of the day. These gross biases, reported earlier as due to the underestimated emissions and overestimated ventilation within the model as discussed by Govardhan et al. $(2015,2016)$, are clearly seen. Additionally, the model fails to capture the bimodal diurnality, though a very weak peak is indicated at some of the stations during the morning, while the evening peaks are almost absent everywhere. However, once the diurnally varying emissions with a steady adjustment factor are prescribed in the models, the simulations (DIEM+AF configuration (red line, Fig. 2)) successfully capture not only the pair of peaks, but also the amplitudes of NSBC mass concentration over most of the observation stations. Moreover, the troughs during afternoon and late-night hours in the measured NSBC mass concentration are also realistically captured (in magnitude and the pattern) in the simulation. Such substantial improvements in the model simulations clearly bring in the effect of incorporating scaledup versions of emissions with a diurnal variation (which is more realistic than constant emissions) in the simulations and emphasize its need. In a stricter sense, the diurnal variation 

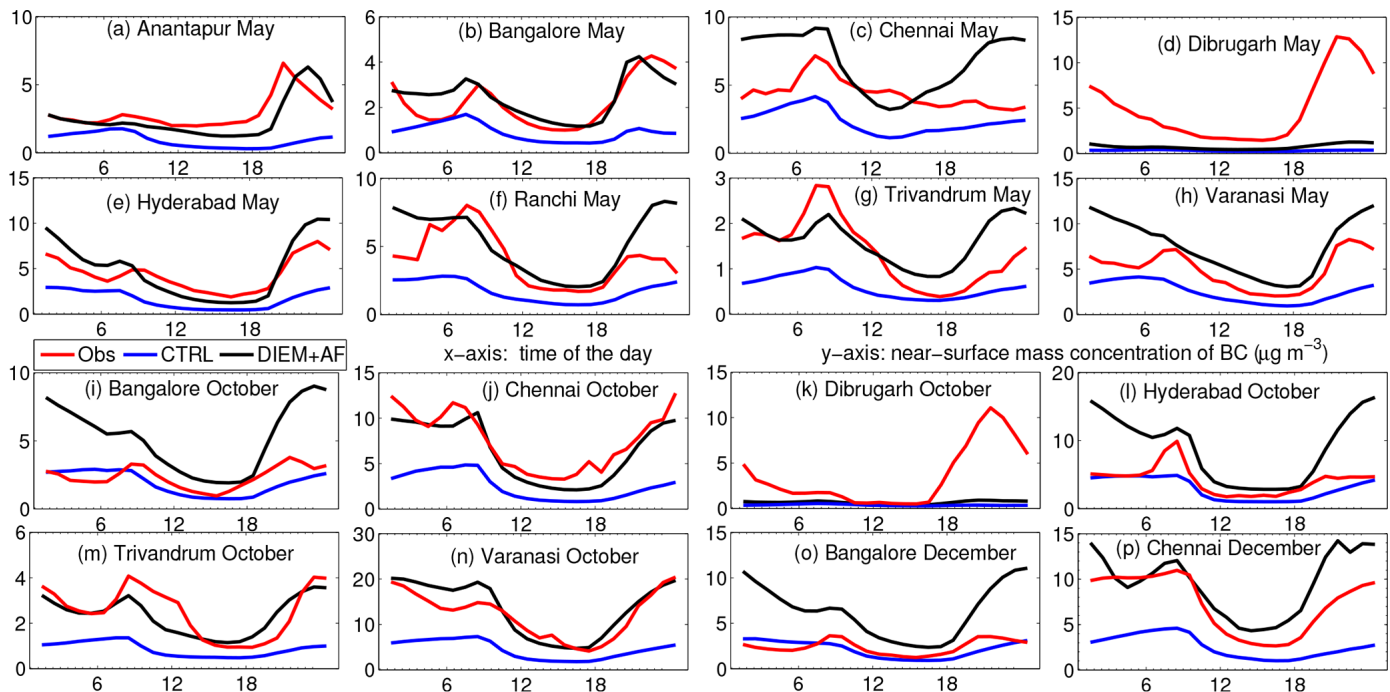

Figure 2. Comparison between the observed monthly-mean diurnal cycle of NSBC and the model simulations in the CTRL and DIEM+AF configurations, over the different ARFI observational stations across the country. The red, blue and black contours correspond to observations and the CTRL and DIEM+AF simulations, respectively.

in emissions of $\mathrm{BC}$ as well as the adjustment factor would vary from station to station depending upon the nature of sources and mesoscale meteorology running over the synoptic scale (Govardhan et al., 2016). Thus, the modified emissions may not necessarily improve the model's performance homogeneously throughout the study domain. This is especially clear from disagreements that still persist between the model (DIEM+AF configuration) and the observations at a few stations (Fig. 2d, Chennai in May, Fig. 2i, Bangalore in October, and Fig. 2l, Hyderabad in October). Nevertheless, in general, the present scheme yields a large improvement over the CTRL simulations.

We next compare the simulated daily-mean NSBC mass concentration with the corresponding observations. Since the CTRL simulations fail to capture the magnitude and the pattern of the diurnal variation (Fig. 2), they significantly underestimate the observed daily-mean values of NSBC mass concentration (as indicated by the blue dots in Fig. 3). The CTRL simulations also yield NSBC mass concentrations within a much narrower range than the measurements. On the other hand, the simulations with diurnally varying emissions and adjustment factors show large improvements (red dots, Fig. 3). The range of the modeled NSBC mass concentration is broadened vis-à-vis CTRL, and the model better agrees with the measurements, especially for higher BC concentrations. Thus, in the DIEM+AF configuration, in addition to the pattern of diurnal variation, the model better captures the magnitudes of daily-mean mass concentrations as well, at several stations. The dotted black line in each scatterplot is the $45^{\circ}$ line, which is a graphical representation of the $y=x$ relationship. It could be clearly seen from the visual inspection that, over most of the observational stations, for
Table 1. Statistics (slope of the best-fit line and the $y$ intercept) of the comparison between the daily-mean values of the observed and modeled NSBC shown in Fig. 3.

\begin{tabular}{llr|r|rr}
\hline Station & Month & \multicolumn{2}{c|}{ Slope } & \multicolumn{2}{c}{$y$ intercept } \\
\cline { 3 - 6 } & & CTRL & DIEM+AF & CTRL & DIEM+AF \\
\hline Anantapur & May & 0.02 & 0.50 & 0.86 & 1.00 \\
\hline Bangalore & May & 0.16 & 0.41 & 0.54 & 1.60 \\
& October & 0.20 & 0.59 & 1.49 & 3.92 \\
& December & 0.34 & 0.94 & 1.41 & 4.34 \\
\hline Chennai & May & 0.24 & 0.67 & 1.30 & 3.80 \\
& October & 0.10 & 0.18 & 1.70 & 4.44 \\
& December & 0.04 & 0.36 & 1.80 & 4.27 \\
\hline Dibrugarh & May & 0.00 & 0.00 & 0.32 & 0.76 \\
& October & 0.01 & 0.02 & 0.28 & 0.54 \\
\hline Hyderabad & May & 0.06 & 0.14 & 1.40 & 4.30 \\
& October & 0.06 & 0.20 & 2.68 & 8.10 \\
\hline Ranchi & May & 0.02 & 0.07 & 1.60 & 4.80 \\
\hline Trivandrum & May & 0.06 & 0.29 & 0.51 & 1.20 \\
& October & 0.05 & 0.36 & 0.74 & 1.50 \\
\hline Varanasi & May & 0.01 & 0.35 & 2.50 & 5.70 \\
& October & 0.12 & 0.33 & 3.01 & 9.49 \\
\hline
\end{tabular}

the DIEM+AF configuration the relationship between modeled and observed NSBC mass concentrations is closer to the ideal (black dotted line). This is confirmed by examining the coefficients of regression analysis of different model simulations with the measurements in Table 1.

The increase in the slope of the best-fit line in the DIEM+AF vis-à-vis CTRL could be clearly noted from columns 3 and 4 of Table 1 for a large number of stations. 

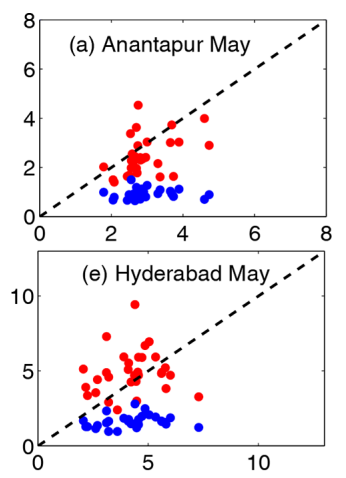

- DIEM+AF Vs Obs • CTRL Vs Obs
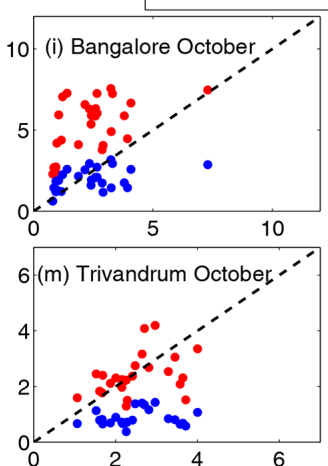
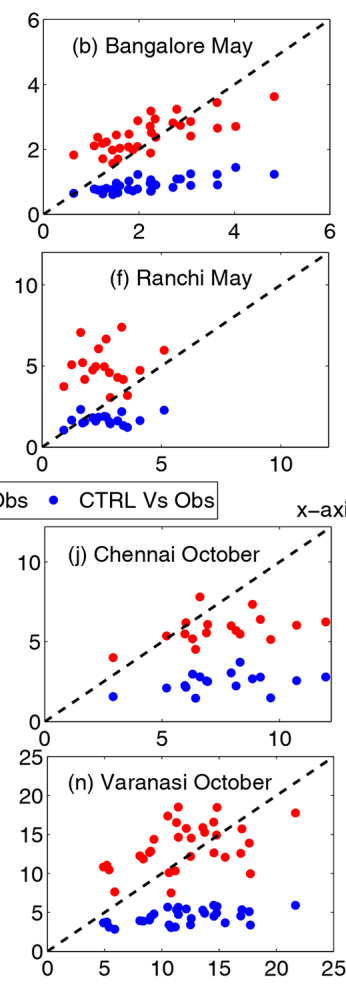
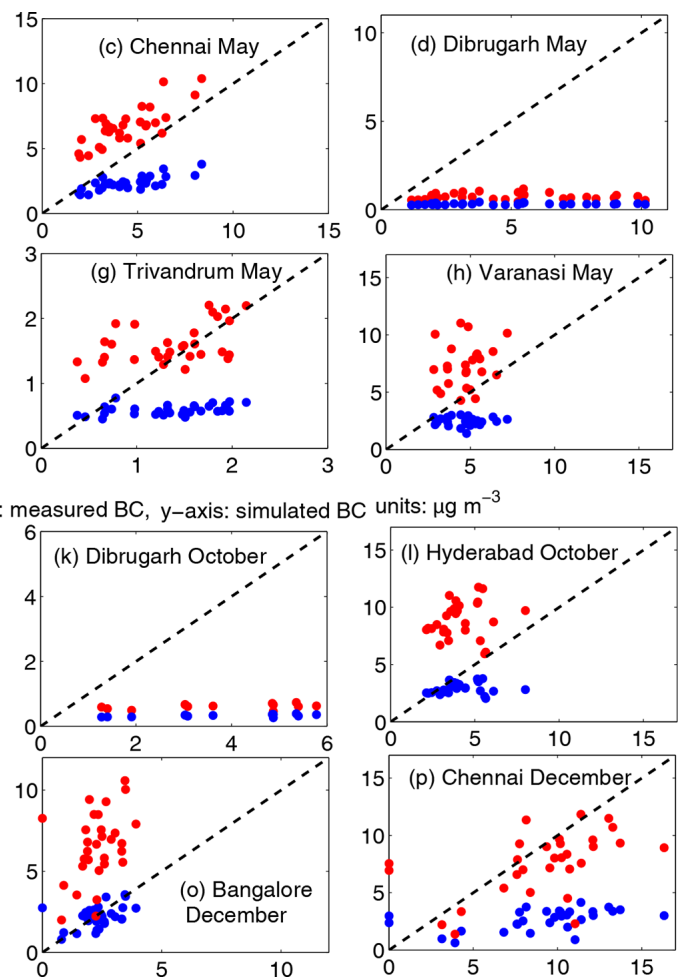

Figure 3. Comparison between the observed daily-mean NSBC and the model-simulated NSBC in the CTRL and DIEM+AF configurations, for the months of May, October and December 2011, over the different ARFI observational stations across the country. The blue dots represent the comparison between the observations and the model simulation in the CTRL configuration, while the red dots represent such comparison for the DIEM+AF configuration. The dotted black line is the $45^{\circ}$ line representing the $y=x$ relationship.

Relatively higher changes in the slope are seen for the semiurban stations like Trivandrum, Anantapur and Varanasi, while no improvement is seen over Dibrugarh and Ranchi. On the other hand, the $y$ intercept over all the stations shows an increase in the DIEM+AF configuration (column 6, Table 1) vis-à-vis the CTRL configuration (column 5, Table 1), especially over stations Hyderabad, Varanasi and Ranchi. Such higher values of the $y$ intercept however indicate that the prescribed modifications in the emissions degrade the performance of the model when ambient NSBC mass concentrations are lower. Despite the improvements over most of the stations, the model still underestimates NSBC mass concentration by a large margin over Ranchi and Dibrugarh (stations located in the eastern and northeastern regions of India, respectively). This is possibly attributed to large underestimation in fossil fuel emissions of $\mathrm{BC}$ in this region. Moreover, Dibrugarh lies in the vicinity of the boundary of the model domain. The Burma region, which is located just east of the model boundary, is known to be a home to biomass burning activities, especially during the pre-monsoon season (Chan et al., 2003; Huang et al., 2016). Also, there are extensive contributions due to oil refineries and brick kilns spread extensively over this region (Gogoi et al., 2017). Considering this, the model's performance in simulating the daily-mean NSBC mass concentration is substantially improved with the prescription of the adjustment factor and diurnally varying emissions over the previous simulations (Nair et al., 2012; Moorthy et al., 2013; Kumar et al., 2015; Govardhan et al., 2015, 2016) over the Indian region.

\subsection{Simulated NSBC mass concentration: implications of diurnality in emissions}

In this section, we attempt to understand the effects of the diurnality in emissions on the simulated NSBC mass concentration. For this, we estimate $\triangle \mathrm{BC}$, where

$$
\begin{aligned}
\Delta \mathrm{BC}(\%)= & \left(\left(\mathrm{NSBC}_{\mathrm{DIEM}}-\mathrm{NSBC}_{\mathrm{CTRL}}\right) / \mathrm{NSBC}_{\mathrm{CTRL}}\right) \\
& \times 100,
\end{aligned}
$$

where $\mathrm{NSBC}_{\mathrm{DIEM}}$ and $\mathrm{NSBC}_{\mathrm{CTRL}}$ are NSBC mass concentrations in the DIEM and CTRL configurations of the model simulation, respectively. Thus, $\triangle \mathrm{BC}$ signifies the effects of the prescribed diurnally varying emissions over the timeinvariant emission scheme. We examine the monthly-mean, 3-hourly averaged $\triangle \mathrm{BC}$ values for the month of May 2011 (as representative) in Fig. 4. As expected, during a day, $\triangle \mathrm{BC}$ values depict a broad range, with its extremes as high as $\pm 40 \%$. During midnight to morning hours (03:00 to 09:00; Fig. 4) $\triangle B C$ shows negative tendencies roughly uniformly over the entire land mass of the region. This signifies that 
the diurnal variation in emissions induces lesser ambient NSBC mass concentration during the nighttime than would have been present if the emissions had no diurnal variations. The maximum negative values $(\sim-40 \%)$ occur during 06:00 h. Similarly, in the evening to midnight sector, $\triangle \mathrm{BC}$ becomes largely positive. This indicates that, owing to the diurnality in emissions, we experience higher ambient NSBC mass concentrations during evening to midnight hours as compared to the time-invariant emissions scenario. Between these two, i.e., from 09:00 to 15:00 h (Fig. 4), $\triangle B C$ values appear mostly close to zero. The positive changes are relatively higher over the Indo-Gangetic Plain region (18:0024:00, Fig. 4), while the negative changes are more predominant over the western part of India (03:00-06:00, Fig. 4). Thus it can be said that the ambient diurnal variation in emissions of BC leads to cleaner mornings and midnights, with more polluted evenings, as compared to the time-invariant emission scenario. Such systematic effects of diurnality in emissions on NSBC mass concentration are also noticed on the land mass of Sri Lanka, an island located near the southern tip of India. On the other hand, the ocean basins within the Indian region do not show such effects (Fig. 4), due to no time-dependent emissions over oceans and also due to weaker ABL dynamics. Thus, the effects of the emission cycle on NSBC mass concentration occur only over the regions where time variation in $\mathrm{BC}$ source strength prevails. On account of negative deviations during midnight to morning hours and positive tendencies during evening to night hours, the net effect of diurnal variation in emissions on NSBC mass concentration on a daily-mean basis appears negligible.

In addition to the diurnal nature of anthropogenic emissions, the dynamics of the atmospheric boundary layer would strongly influence the near-surface BC concentration, as has been shown in several studies (Nair et al., 2012; Moorthy et al., 2013; Govardhan et al., 2015). As such, we examine the relationship between $\triangle \mathrm{BC}$ and the planetary boundary layer height (PBLH) over six grid boxes of dimension $1^{\circ} \times 1^{\circ}$ (Fig. 5), such that the grid boxes together cover the regions with higher magnitudes of $\triangle \mathrm{BC}$. The correlation coefficients between hourly values of absolute magnitude of $\triangle \mathrm{BC}(|\triangle \mathrm{BC}|)$ and the simulated PBLH in the CTRL configuration $\left(\mathrm{PBLH}_{\mathrm{CTRL}}\right)$ are computed and are listed in Table 2. The significance of the correlation coefficients has been tested using the $t$ test (Lowry, 2014). The correlations are found to be significant, with $p$ value $<0.0001$. The consistent and significant (with $p<0.0001$ ) negative correlation clearly vindicates the role of the boundary layer in modulating the NSBC concentrations. This behavior of $\triangle \mathrm{BC}$ is seen in Fig. 4 also, where the absolute magnitudes of $\triangle B C$ are higher during the evening to early morning hours (periods when the boundary layer is normally shallower) and are lower during afternoon periods when the boundary layer is deeper. While the above coupling explains the behavior of $|\triangle \mathrm{BC}|$, to understand the causes behind the sign of $\triangle \mathrm{BC}(+$ or - ), we computed the correlation coefficients (CCs) be-
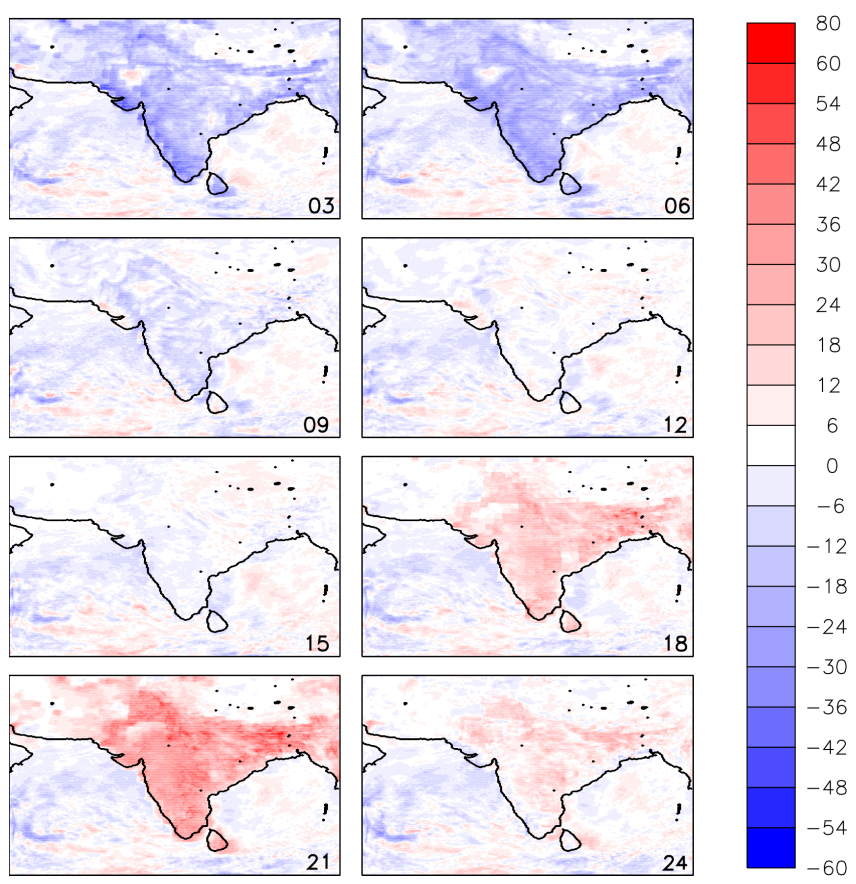

Figure 4. Monthly-mean 3-hourly averaged values of $\triangle \mathrm{BC}(\%)$. The IST hours for each plot have been written in the bottom-right corner. The $\triangle \mathrm{BC}$ values are plotted for May 2011 as a representative.

Table 2. The correlation coefficient between $|\triangle B C|$ and the simulated PBL height in the CTRL configuration for the six chosen $1^{\circ} \times 1^{\circ}$ grid boxes.

\begin{tabular}{llll}
\hline Region & May & October & December \\
\hline Delhi & $-0.50 \pm 0.03$ & $-0.47 \pm 0.03$ & $-0.53 \pm 0.03$ \\
Gangetic Plain 1 & $-0.36 \pm 0.03$ & $-0.51 \pm 0.03$ & $-0.49 \pm 0.03$ \\
Gangetic Plain 2 & $-0.32 \pm 0.03$ & $-0.49 \pm 0.03$ & $-0.46 \pm 0.03$ \\
Bengal & $-0.38 \pm 0.03$ & $-0.55 \pm 0.03$ & $-0.55 \pm 0.03$ \\
CI & $-0.51 \pm 0.03$ & $-0.60 \pm 0.02$ & $-0.46 \pm 0.03$ \\
SI & $-0.55 \pm 0.03$ & $-0.58 \pm 0.02$ & $-0.54 \pm 0.03$ \\
\hline
\end{tabular}

tween the hourly values of $\triangle \mathrm{BC}$ and the prescribed diurnal variation in emissions (Fig. 1) over the same $1^{\circ} \times 1^{\circ}$ grid boxes (Fig. 5) for different values of "lead hour" between them (Fig. 6), for all 3 months of the model simulation. Here lead $k$ means the prescribed emission cycle leads $\triangle \mathrm{BC}$ by " $k$ " hours or, in other words, the effect of emission at a given time " $t$ " is examined on $\Delta \mathrm{BC}$ at " $t+k$ " hours.

It clearly emerges that $\triangle \mathrm{BC}$ holds a strong positive relationship with the diurnal emission cycle, indicated by higher values of CC (Fig. 6a-c). The CC increases with increasing values of the lead hour $(k)$, the maximum occurring for $k$ values of 3 to 4 . This indicates that the effects of temporal variations in the emissions are perceived most on the near-surface $\mathrm{BC}$ concentrations after 3 to $4 \mathrm{~h}$ of the actual emissions. This is also evident from Figs. 4 and 1, where the minimum in emissions is seen to occur at 03:00, while that in $\triangle \mathrm{BC}$ oc- 


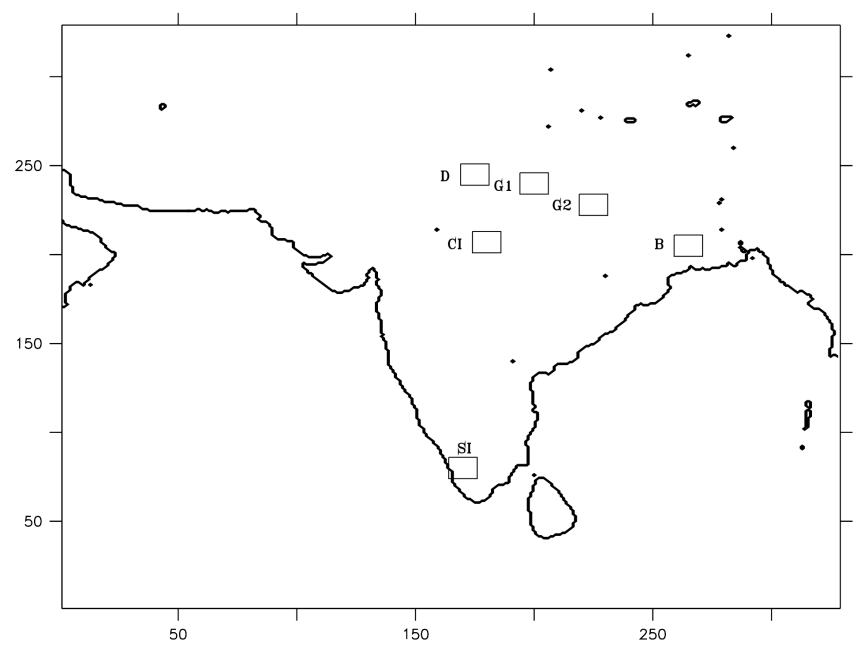

Figure 5. The $1^{\circ} \times 1^{\circ}$ grid boxes chosen for the analysis of $\Delta \mathrm{BC}$. The meanings of the abbreviations are as follows: D - Delhi, G1 Gangetic Plain 1, G2 - Gangetic Plain 2, B - Bengal, CI - central India and SI - southern India.

curs at 06:00. A similar delay is also seen between maxima in emissions $(18 \mathrm{~h})$ and maxima in $\triangle \mathrm{BC}(21 \mathrm{~h})$ (Figs. 4 and 1). As $\triangle \mathrm{BC}$ is the resultant of both boundary layer dynamics and the emissions cycle, it is the differences in the diurnality of them that would determine the optimum $k$ value when the effect maximizes on NSBC mass concentration. This is examined further by computing the correlation coefficients between $\triangle \mathrm{BC}$ and the emission cycle separately for the sunlit (period when the boundary layer is dynamic) and post-sunset hours (when the boundary layer collapses to the nocturnal layer). During the sunlit/morning-afternoon hours (07:30-17:30 IST), when the thermal convection is significant, the CC values maximize at around a lead hour of 5-6 h (Fig. 6d-f) (as the turbulence facilitates better dispersion of the emissions), while during the stable hours of evening to night (18:30-06:30 IST), it maximizes within 2-3 h (Fig. 6d$\mathrm{f}$ ) as the volume available for dispersion is smaller. It can be noticed that $\triangle \mathrm{BC}$ and the emission cycle are negatively correlated ( $\mathrm{CC}$ values being negative) for the first few lead hours of the morning time (Fig. 6d-f). During the morning hours, the emissions show an increasing trend (Fig. 1), while $\triangle B C$ appears to be negative, due to the deepening of the boundary layer and the consequent dispersion of $\mathrm{BC}$, which do not allow the increased emissions to show the same effect on concentrations immediately. A deviation from this pattern is seen during winter (December), for morning to afternoon hours (Fig. 6f), in the regions GP2, SI and Bengal, which depict a positive $\mathrm{CC}$ between $\triangle \mathrm{BC}$ and the emission cycle, and the maximum $\mathrm{CC}$ is seen around $3-5 \mathrm{~h}$, as opposed to $5-6 \mathrm{~h}$ for the other regions (GP1, Delhi and CI) and the other seasons (Fig. 6d-e). Examining the simulated PBLH over these regions, we find that the monthly-mean daily maximum values are 804, 932 and $672 \mathrm{~m}$, respectively, substantially lower than those over the other three regions (GP1 - 1019 m, Delhi $1214 \mathrm{~m}$ and CI $-1923 \mathrm{~m}$ ), showing a larger vertical confinement at the former three stations and enabling NSBC mass concentration to respond to emission changes much faster than the latter three stations. Nevertheless, in general, it can be noticed that the simulated concentrations possess some "memory" of the emission scenario during the recent hours of the stable boundary layer. This "memory" of the simulated concentrations plays a crucial role in causing a delayed effect of the prescribed diurnal variations in emissions on the simulated concentrations. This also explains the higher values of the $\mathrm{CC}$ during the evening-night sector than during the morning-afternoon daytime hours, as the dynamics of the PBL in the former case enables quicker response of NSBC mass concentration by enhancing the confinement by shallow PBL, while in the latter case the deeper boundary layer opposes the response to the emission changes by allowing enhanced dispersion within the deeper PBL. Thus, it is evident that the response of the simulated NSBC mass concentration to the time-varying emissions is modulated by the convective mixing within the atmospheric boundary layer. This analysis also underlines that any modification to emissions of pollutants during stable boundary layer hours of evening to morning would not only affect the air quality for that time period, but also would influence the air-quality scenario for the subsequent sunlit hours of the unstable boundary layer and is an important input for mitigation planning.

\subsection{Effects of modified BC emissions on the simulated AOD}

While near-surface $\mathrm{BC}$ concentration has implications for health and air quality, one of the most important aerosol parameters for regional/global climate impact assessment is the columnar aerosol optical depth (AOD), which is the vertical integral from the surface to top-of-the-atmosphere (TOA), of the extinction caused by aerosols. Despite its significance, inaccurate simulation of AOD over the Indian region has been a common problem among multiple global as well as regional chemistry transport models (Nair et al., 2012; Pan et al., 2015; Feng et al., 2016; Govardhan et al., 2015, 2016). The models tend to underestimate/overestimate the regional AODs due to several factors, including unrealistic emissions of anthropogenic aerosol species (Govardhan et al., 2015) and incorrect simulations of near-surface humidity (Pan et al., 2015; Feng et al., 2016). In a few previous studies (Govardhan et al., 2015, 2016), it was noticed that while WRF-Chem replicates the spatial pattern of satelliteretrieved AOD fairly correctly, it underestimates the magnitudes by factors ranging from 1.5 to 2 over the Indian region. In view of effects seen with modified emission on NSBC mass concentration, we examined the effects of this on the simulated AOD within WRF-Chem over the Indian region. A detailed comparison of model-simulated AOD in the CTRL configuration with the satellite products (MODIS and MISR) 
(a) May: entire day

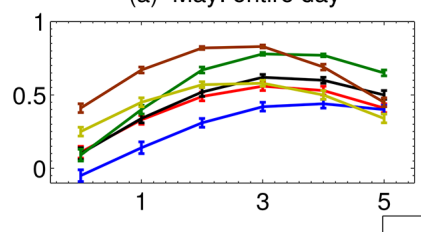

(b) October: entire day

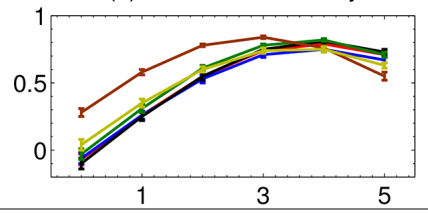

(c) December: entire day

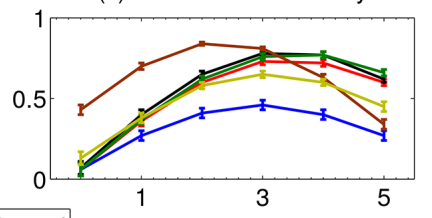

(d) May: morning-afternoon hours

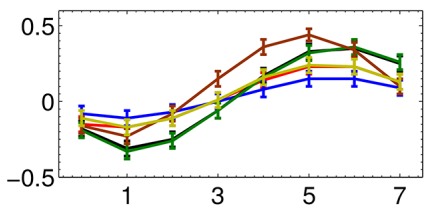

(e) October: morning-afternoon hours

(f) $D$
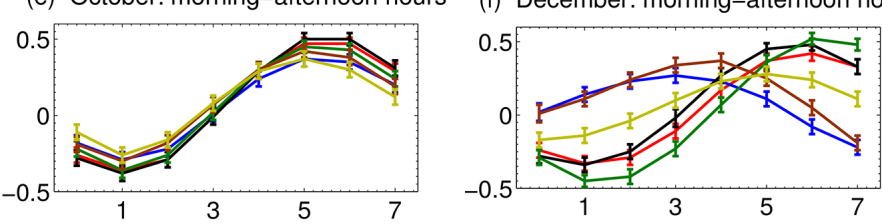

$\mathrm{X}$-axis: lead-hour between emission cycle and $\triangle \mathrm{BC}$

$y$-axis: correlation coefficient between emission cycle and $\triangle B C$

(g) May: evening-night hours

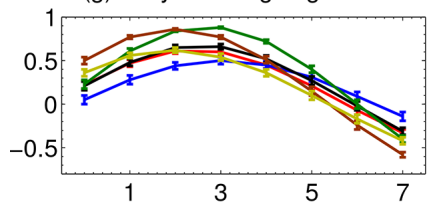

(h) October: evening-night hours
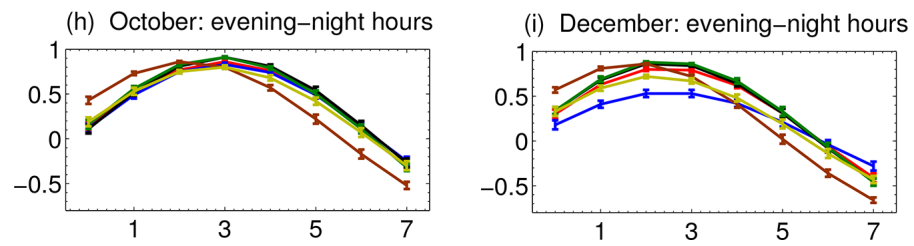

Figure 6. Correlation coefficients between hourly values of the emission cycle (i.e., the diurnality factor) and $\Delta \mathrm{BC}$, at different lead hours considering all times of the day (00:00-24:00 IST) in (a) May, (b) October and (c) December; considering only the morning-afternoon hours (07:30-17:30 IST) in (d) May (e) October and (f) December; and considering only the evening-night hours (18:30-06:30 IST) in (d) May, (e) October and (f) December. For (a)-(c), (d)-(f) and (g)-(i), all the coefficient values with magnitudes greater than $0.15,0.2$ and 0.22 , respectively, are significant, with $p<0.0001$. The meanings of the abbreviations are as follows: GP1 - Gangetic Plain 1; GP2 - Gangetic Plain 2. The other abbreviations are defined in Fig. 5.

has already been presented in Govardhan et al. (2016); here, we mainly examine the effects of modified $\mathrm{BC}$ emissions on the model-simulated AOD.

We compare WRF-Chem-simulated AOD (CTRL and DIEM+AF configurations) with MODIS-retrieved AOD (at $550 \mathrm{~nm}$ ) for the month of May 2011 as representative. Though the satellite-retrieved AOD over land may have larger uncertainties due to the heterogeneity in the surface reflectance (Jethva et al., 2009), we use such products in our study for model evaluation purposes, mainly due to their spatial coverage. The satellite-retrieved AOD (Fig. 7a) shows high values (0.6-0.8) over the Indo-Gangetic Plain (IGP) and off the eastern coast of India, the causes of which are already discussed in previous studies (Govardhan et al., 2015, 2016). Over the rest of the land mass, moderate AOD values (up to $0.6)$ are noticed, with a regional hotspot over central-eastern India (Fig. 6a). Away from the land mass, AOD gradually reduces over the water bodies (Arabian Sea and the Bay of Bengal). In general, due to prevailing winds (westerly), the Bay of Bengal is seen to be under a larger aerosol burden visà-vis the Arabian Sea (Fig. 7a). The model, WRF-Chem, in the CTRL configuration (Fig. 7b), though, captures the AOD hotspot over the IGP region and off the eastern coast of India (as shown by Govardhan et al., 2016, and in Fig. 7b), and it largely underestimates the magnitudes. In the DIEM+AF configuration (Fig. 7c), the pattern of model-simulated AOD is roughly similar to the CTRL configuration (Fig. 7b); how- ever, the magnitudes have increased as expected (due to the adjustment factor). The AOD hotspots over the IGP and eastern coast of India become more intense in the DIEM+AF configuration (Fig. 7c), while the AOD magnitudes over the rest of the region (land mass and oceans) show relatively lesser changes (Fig. 7c). It can well be noticed that, even in the DIEM+AF configuration, the model still underestimates AOD over the Indian region vis-à-vis satellite-retrieved values. The quantification of such underestimation is provided in Table 3. The entire model domain has been divided into 10 regional boxes. The boxes are so chosen that they individually capture regions with distinct AOD features, while together they cover the entire model domain. The names and latitude-longitude boundaries of the boxes are listed in columns 1 and 2 of Table 3 . It can be noticed from Table 3 (columns 3 and 4) that WRF-Chem (in the DIEM+AF configuration) still underestimates the MODIS-retrieved AOD over the entire Indian region, by factors ranging from 1.24 to 2.27 , being higher over the land regions (column 5 , rows $2-7$, Table 3) than over the oceanic regions (column 5, rows 8-11, Table 3). Even over the land mass, the underestimations are higher over the regions with a high AOD burden (NIGP and $\mathrm{NW}$ ) as compared to the relatively cleaner regions (CI, SI and Bengal). Similarly, over the oceanic bodies, higher underestimations are seen over the regions which are closer to land masses (NAS and $\mathrm{HBoB}$ ) as compared to farther oceanic regions (AS and $\mathrm{BoB}$ ). Thus, despite the modifications in $\mathrm{BC}$ 
Table 3. Comparison of WRF-Chem-simulated AOD with MODIS. AF: adjustment factor (MODIS AOD/model AOD). The meanings of the abbreviations are as follows. NIGP: North India and Gangetic plains; NW: northwestern part of the Indian sub-continent; CI: central India; SI: southern India; LNAS: land mass north of the Arabian Sea; AS: Arabian Sea; NAS: northern part of the Arabian Sea; BoB: Bay of Bengal; HBoB: head (northern) part of the Bay of Bengal.

\begin{tabular}{lrrrr}
\hline Region & $\begin{array}{r}\text { Latitude }\left({ }^{\circ} \mathrm{N}\right), \\
\text { longitude }\left({ }^{\circ} \mathrm{E}\right)\end{array}$ & WRF-Chem & MODIS & AF \\
\hline NIGP & $73: 87,24: 30$ & 0.31 & 0.58 & 1.85 \\
NW & $67: 73,24: 30$ & 0.26 & 0.60 & 2.27 \\
CI & $73: 84,18: 24$ & 0.29 & 0.43 & 1.51 \\
SI & $74: 80,10: 18$ & 0.32 & 0.45 & 1.43 \\
LNAS & $60: 66.5,25.5: 31$ & 0.23 & 0.44 & 1.91 \\
Bengal & $88: 92,23: 28$ & 0.36 & 0.48 & 1.33 \\
AS & $58: 72,6: 17$ & 0.19 & 0.24 & 1.32 \\
NAS & $60: 66,18: 25$ & 0.27 & 0.43 & 1.59 \\
BoB & $83: 94,8: 16$ & 0.28 & 0.34 & 1.24 \\
HBoB & $87: 92,17: 21$ & 0.39 & 0.53 & 1.36 \\
\hline
\end{tabular}

emissions, the simulated AOD within WRF-Chem still underestimates the satellite products. This is not surprising, as $\mathrm{AOD}$ is the resultant extinction of multiple aerosol species in addition to BC, and contribution of BC to AOD over the Indian region has been reported be roughly around $11 \%-17 \%$ (Satheesh et al., 1999; Ramanathan et al., 2001; Srivastava et al., 2011). Moreover, the diurnal variation and the prescribed multiplication factor on the BC emissions are limited to near the surface, while in the column their effects would be negligible. A further investigation is needed to understand the causes behind underestimation of AOD over the Indian region in WRF-Chem.

Notwithstanding the limited effect of BC on AOD simulations over the Indian region, we next attempt to delineate the effects of the diurnally varying emission cycle (Fig. 1), and the multiplication factor on $\mathrm{BC}$ emissions, on the simulated AOD. For that, we compute $\triangle \mathrm{AOD}_{\text {cycle }}, \triangle \mathrm{AOD}_{\mathrm{AF}}$ and $\triangle \mathrm{AOD}_{\text {cycle }+\mathrm{AF}}$, where

$$
\begin{aligned}
& \Delta \mathrm{AOD}_{\text {cycle }}=\mathrm{AOD}_{\mathrm{DIEM}}-\mathrm{AOD}_{\mathrm{CTRL}}, \\
& \Delta \mathrm{AOD}_{\mathrm{AF}}=\mathrm{AOD}_{\mathrm{DIEM}+\mathrm{AF}}-\mathrm{AOD}_{\mathrm{DIEM}}, \\
& \Delta \mathrm{AOD}_{\text {cycle }}+\mathrm{AF}=\mathrm{AOD} \text { DIEM }+\mathrm{AF}-\mathrm{AOD}_{\mathrm{CTRL}} .
\end{aligned}
$$

Thus, $\Delta \mathrm{AOD}_{\text {cycle }}, \triangle \mathrm{AOD}_{\mathrm{AF}}$ and $\triangle \mathrm{AOD}_{\text {cycle }+\mathrm{AF}}$, respectively, represent the modification in AOD due to the emission cycle (Fig. 7d), the adjustment factor of 3 on BC emissions (Fig. 7e) and both (Fig. 7f). As can be noted, the prescription of only the diurnal variation of emissions induces negligible changes $(5 \%)$ in the monthly-mean AOD (Fig. 7d). Such negligible changes in AOD are expected as the diurnal variation merely re-distributes the emissions along the vertical while maintaining the same daily accumulated value. Hence, though the emission cycle induces larger changes in the hourly values of near-surface concentrations, it leaves
AOD almost unperturbed. The changes in AOD due to the prescription of a spatially uniform adjustment factor of 3 to the emissions of $\mathrm{BC}$ are seen to be relatively higher over the IGP, over northeastern India and off the eastern coast of India (Fig. 7e). The changes are mainly seen over the regions with high emissions of $\mathrm{BC}$ and over the Bay of Bengal, which is affected mainly due to advection from the adjoining continents. The changes in AOD (Fig. 7e) appear to be around $10 \%-15 \%$ of AOD in the CTRL configuration (Fig. 7b). Thus, as expected, a large fraction of the changes in AOD in DIEM+AF vis-à-vis the CTRL configuration are due to the prescription of the adjustment factor on $\mathrm{BC}$ emissions (Fig. 7f). Thus, the simulated AOD (in the DIEM+AF configuration) still remains an underestimate over the Indian land mass by factors of more than 1.5. Possible causes behind such discrepancies could be related to the model-simulated vertical profile of aerosols and the state of mixing of aerosol in the model, which are to be examined separately.

The realistic simulations of aerosol over one of the global hotspots, the Indian region, assume significance due to numerous socio-economic factors. In this context, it is imperative to continuously examine and improve the performance of the models in simulating the regional aerosol loading. Learning from the previous studies (Govardhan et al., 2015, 2016), we made modifications in the WRF-Chem model in order to improve its performance in simulating the aerosol burden over the region. The subsequent large agreements between the simulated NSBC mass concentration and the station measurements over the Indian region shown in this study, on timescales as fine as an hour, are noticed for the first time. Such improvements substantially enhance the applicability of WRF-Chem in characterizing the aerosol loading over the region. This study could thus serve as a guideline for further model development studies over the Indian region. We, in this study, prescribe a spatially uniform diurnal cycle of emissions, which could be an idealistic assumption. In reality, the specification of a regionally varying diurnal variation would be more appropriate given the heterogeneity of the emission sources. However, this would need extensive characterization of the diurnality of emissions in distinct regions/seasons. Such studies do not exist over India, and it is hoped that our present work may provide motivation for initiating such studies. It is further noted that the model still underestimates AOD (which is a common issue among many models), which could be examined in future studies. One of the critical parameters in AOD computation is the simulated vertical distribution of aerosol. The performance of WRFChem in simulating altitude distribution of aerosols needs to be evaluated in this context. Another important parameter is the assumptions about the state of mixing of aerosol in general and $\mathrm{BC}$ in particular, which significantly governs the resulting optical and radiative effects of aerosol (Jacobson, 2001; Chandra et al., 2004; Peng et al., 2016). In these regards, the realistic state of mixing of aerosol over the Indian region (as revealed by a recent study: Hariram et al., 2018) 

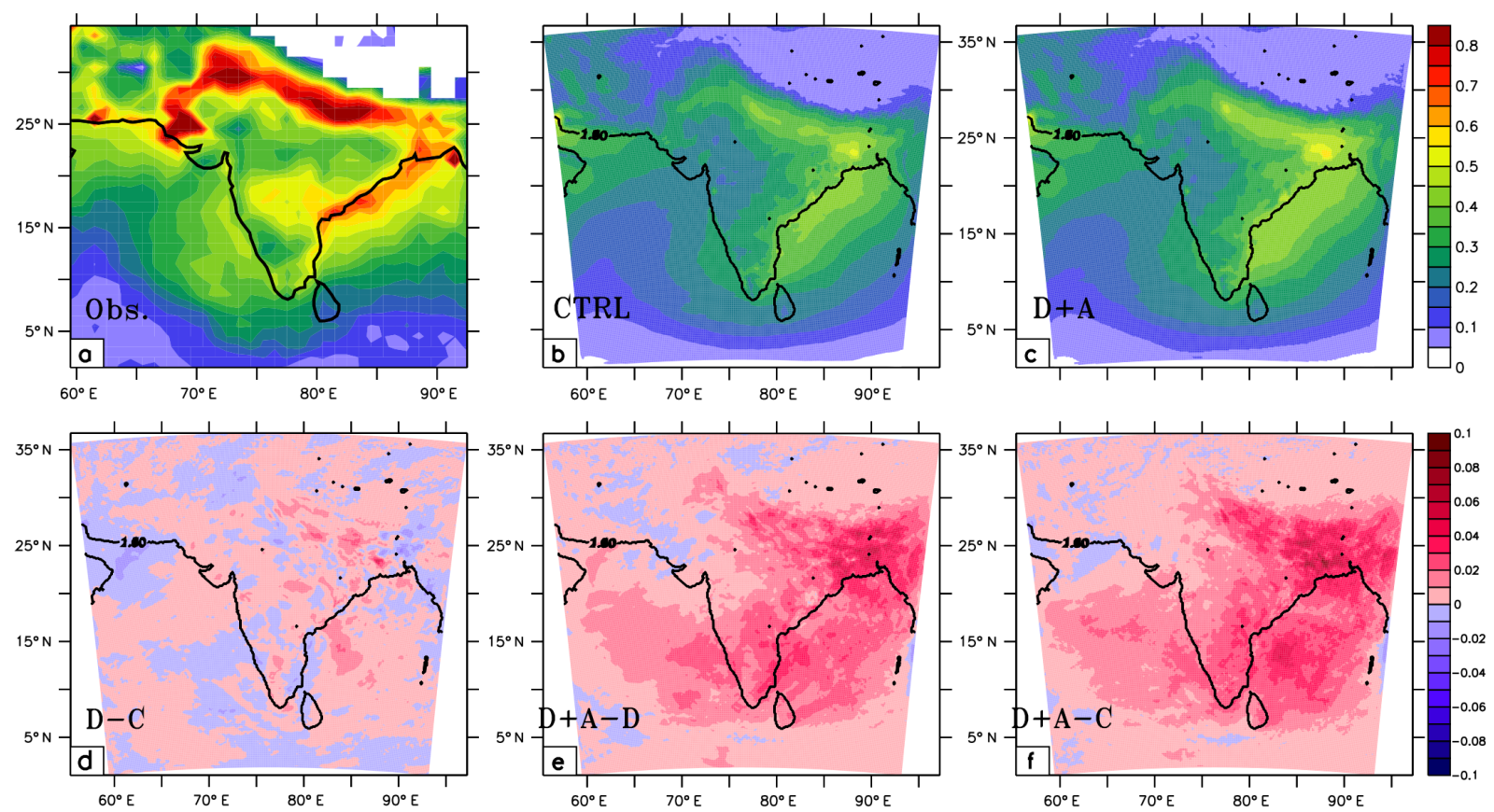

Figure 7. Comparison between (a) satellite-retrieved AOD (MODIS), (b) model-simulated AOD in the CTRL configuration and (c) modelsimulated AOD in the DIEM+AF configuration. The bottom panels show the effects of the modifications in emissions on AOD simulations: (d) model-simulated AOD for the DIEM-CTRL configurations, which shows the effect of the prescription of the diurnal variation in emissions on AOD. (e) Model-simulated AOD for the DIEM+AF-DIEM configurations, which shows the effect of the prescription of the adjustment factor on emissions on AOD. (f) Model-simulated AOD for the DIEM+AF-CTRL configurations, which shows the effect of the prescription of both the diurnal variation and the adjustment factor on emissions on AOD. All the plots represent the month of May 2011.

could be examined and prescribed in the models to reveal its role in unrealistic simulations of AOD. This study has also revealed important information about the response of NSBC mass concentration to the changes in emissions. The advantages of reducing the emissions during the stable boundary layer hours with regards to local air quality are highlighted well by this study. It is also noted that the strong impact of nighttime reduction in emissions on the morning-time NSBC mass concentration allows enhanced emissions during the morning hours without compromising on air quality. This information will be vital from an air-quality management perspective.

\section{Conclusions}

With a motive to improve the performance of a regional chemistry transport model, WRF-Chem, in simulating nearsurface $\mathrm{BC}$ mass concentration, the anthropogenic emissions of $\mathrm{BC}$ in the model are modified. The modifications include prescription of a diurnal variation and scaling up of the magnitudes by a spatially uniform factor of 3 . In addition to examining the performance of the model, the role that the ambient diurnal variation in emissions plays in governing the simulated near-surface BC mass concentration has also been analyzed in this study. The main conclusions are as follows.
1. The modifications substantially improve the performance of the model in simulating near-surface BC mass concentrations, giving better agreements with station measurements on timescales as fine as an hour.

2. The effects of diurnal variation in emissions on the simulated near-surface BC mass concentration are seen mainly during the hours of shallower boundary layer height.

3. The diurnal nature of the $\mathrm{BC}$ emissions induces cleaner (more polluted) morning (evening to nights) hours visà-vis a temporally independent emission scenario. However, on the daily-mean basis, the effects of diurnal variation in emissions on the near-surface BC mass concentration turn out be negligible due to cancellation of positive effects during evening-night hours and negative effects during morning hours.

4. On average, the effects of the prescription of diurnal variation in emissions on the simulated near-surface $\mathrm{BC}$ mass concentration are perceived a maximum of 3-4h after emissions. The effects are noticed quicker (2-3 h) during the hours of a stable boundary layer and later (5-6h) during the sunlit hours of an unstable boundary layer. 
5. The prescribed modifications in emissions alter the columnar AOD by $\sim 10 \%-15 \%$; however, it is still underestimated vis-à-vis the satellite retrievals.

Code availability. An open-source online regional chemistry transport model, WRF-Chem, was used to perform the simulations carried out in this study. The model is freely available at http://www2. mmm.ucar.edu/wrf/users/ (last access: June 2019).

Author contributions. GG carried out the experiments, analyzed the results and wrote the manuscript. SKS conceived the experiment, led the discussions, fine-tuned the experiments and contributed to the manuscript. KKM contributed to the discussions, fine-tuned the experiments, put the results in perspective and revised and improvised the manuscript. RSN participated in designing the experiment and analyzing the results.

Competing interests. The authors declare that they have no conflict of interest.

Acknowledgements. The computations for this study were carried on the computational cluster funded jointly by the Department of Science and Technology FIST program (DST-FIST), the Divecha Centre for Climate Change and the ARFI project of the Indian Space Research Organisation (ISRO). We would like to thank the ARFI project for providing data regarding near-surface measurements of BC carried out over India. This work is partially supported by MoES (grant no. MM/NERC-MoES-1/2014/002) under the South West Asian Aerosol Monsoon Interactions (SWAAMI) project. The authors would also like to thank the Computational and Information Systems Laboratory (CISL-NCAR) for the Research Data Archive.

Financial support. This research has been supported by the Ministry of Earth Sciences (grant no. MM/NERC-MoES-1/2014/002).

Review statement. This paper was edited by B. V. Krishna Murthy and reviewed by two anonymous referees.

\section{References}

Chakraborty, A., Satheesh, S. K., Nanjundiah, R. S., and Srinivasan, J.: Impact of absorbing aerosols on the simulation of climate over the Indian region in an atmospheric general circulation model, Ann. Geophys., 22, 1421-1434, https://doi.org/10.5194/angeo22-1421-2004, 2004

Chan, C. Y., Chan, L. Y., Harris, J. M., Oltmans, S. J., Blake, D. R., Qin, Y., Zheng, Y. G., and Zheng, X. D.: Characteristics of biomass burning emission sources, transport, and chemical speciation in enhanced springtime tropospheric ozone profile over Hong Kong, J. Geophys. Res.-Atmos., 108, ACH 3-1-ACH $3-$ 13, https://doi.org/10.1029/2001JD001555, 2003.
Chandra, S., Satheesh, S. K., and Srinivasan, J.: Can the state of mixing of black carbon aerosols explain the mystery of "excess" atmospheric absorption?, Geophys. Res. Lett., 31, L19109, https://doi.org/10.1029/2004GL020662, 2004.

Cherian, R., Venkataraman, C., Quaas, J., and Ramachandran, S.: GCM simulations of anthropogenic aerosol-induced changes in aerosol extinction, atmospheric heating and precipitation over India, J. Geophys. Res.-Atmos., 118, 2938-2955, https://doi.org/10.1002/jgrd.50298, 2013.

Chin, M., Diehl, T., Dubovik, O., Eck, T. F., Holben, B. N., Sinyuk, A., and Streets, D. G.: Light absorption by pollution, dust, and biomass burning aerosols: a global model study and evaluation with AERONET measurements, Ann. Geophys., 27, 3439-3464, https://doi.org/10.5194/angeo-27-3439-2009, 2009.

Davidson, C. I., Phalen, R. F., and Solomon, P. A.: Airborne Particulate Matter and Human Health: A Review, Aerosol Sci. Tech., 39 737-749, https://doi.org/10.1080/02786820500191348, 2005.

Feng, Y., Cededdu, M., Kotamarthi, V. R., Renju, R., and Suresh Raju, S.: Humidity bias and effect on simulated aerosol optical properties during the Ganges Valley Experiment, Curr. Sci., 111, 93-100, https://doi.org/10.18520/cs/v111/i1/93-100, 2016.

Ganguly, D., Ginoux, P., Ramaswamy, V., Winker, D. M., Holben, B. N., and Tripathi, S. N.: Retrieving the composition and concentration of aerosols over the Indo-Gangetic basin using CALIOP and AERONET data, Geophys. Res. Lett., 36, L13806, https://doi.org/10.1029/2009GL038315, 2009.

Gogoi, M. M., Babu, S. S., Moorthy, K. K., Bhuyan, P. K., Pathak, B., Subba, T., Chutia, L., Kundu, S. S., Bharali, C., Borgohain, A., Guha, A., De, B. K., Singh, B., and Chin, M.: Radiative effects of absorbing aerosols over northeastern India: Observations and model simulations, J. Geophys. Res.-Atmos., 122, 1132 1157, https://doi.org/10.1002/2016JD025592, 2017.

Goto, D., Takemura, T., Nakajima, T., and Badarinath, K.: Global aerosol model-derived black carbon concentration and single scattering albedo over Indian region and its comparison with ground observations, Atmos. Environ., 45, 3277-3285, https://doi.org/10.1016/j.atmosenv.2011.03.037, 2011.

Govardhan, G., Nanjundiah, R., Satheesh, S., Krishnamoorthy, K., and Kotamarthi, V.: Performance of WRF-Chem over Indian region: Comparison with measurements, J. Earth Syst. Sci., 124, 875-896, https://doi.org/10.1007/s12040-015-0576-7, 2015.

Govardhan, G. R., Nanjundiah, R. S., Satheesh, S., Moorthy, K. K., and Takemura, T.: Inter-comparison and performance evaluation of chemistry transport models over Indian region, Atmos. Environ., 125, 486-504, https://doi.org/10.1016/j.atmosenv.2015.10.065, 2016.

Goyal, P. and Krishna, T.: Various Methods of Emission Estimation of Vehicular Traffic in Delhi, Transpor. Res. D-Tr. E., 3, 309317, https://doi.org/10.1016/S1361-9209(98)00009-1, 1998.

Hariram, C. R., Govardhan, G., Manoj, M. R., Anand, N. S., Kannan, K., Satheesh, S. K., and Moorthy, K. K.: Morphology, Chemical Composition and Mixing State of Atmospheric Aerosols from Two Contrasting Environments in Southern India, Atmos. Chem. Phys. Discuss., https://doi.org/10.5194/acp-2018745, 2018.

Hazra, A., Mukhopadhyay, P., Taraphdar, S., Chen, J.-P., and Cotton, W. R.: Impact of aerosols on tropical cyclones: An investigation using convection-permitting model 
simulation, J. Geophys. Res.-Atmos., 118, 7157-7168, https://doi.org/10.1002/jgrd.50546, 2013.

Herbener, S. R., van den Heever, S. C., Carrió, G. G., Saleeby, S. M., and Cotton, W. R.: Aerosol Indirect Effects on Idealized Tropical Cyclone Dynamics, J. Atmos. Sci., 71, 2040-2055, https://doi.org/10.1175/JAS-D-13-0202.1, 2014.

Huang, W.-R., Wang, S.-H., Yen, M.-C., Lin, N.-H., and Promchote, P.: Interannual variation of springtime biomass burning in Indochina: Regional differences, associated atmospheric dynamical changes, and downwind impacts, J. Geophys. Res.-Atmos., 121, 10016-10028, https://doi.org/10.1002/2016JD025286, 2016.

Jacobson, M. Z.: Strong radiative heating due to the mixing state of black carbon in atmospheric aerosols, Nature, 409, 695-697, https://doi.org/10.1038/35055518, 2001.

Jethva, H., Satheesh, S., Srinivasan, J., and Moorthy, K.: How Good is the Assumption About Visible Surface Reflectance in MODIS Aerosol Retrieval Over Land? A Comparison With Aircraft Measurements Over an Urban Site in India, IEEE T. Geosci. Remote, 47, 1990-1998, https://doi.org/10.1109/TGRS.2008.2010221, 2009.

Kumar, R., Barth, M. C., Pfister, G. G., Nair, V. S., Ghude, S. D., and Ojha, N.: What controls the seasonal cycle of black carbon aerosols in India?, J. Geophys. Res.-Atmos., 120, 7788-7812, https://doi.org/10.1002/2015JD023298, 2015.

Lau, K., Kim, M., and Kim, K.: Asian summer monsoon anomalies induced by aerosol direct forcing: the role of the Tibetan Plateau, Clim. Dynam., 26, 855-864, https://doi.org/10.1007/s00382006-0114-z, 2006.

Lau, W. K. M., Kim, M.-K., Kim, K.-M., and Lee, W.-S.: Enhanced surface warming and accelerated snow melt in the Himalayas and Tibetan Plateau induced by absorbing aerosols, Environ. Res. Lett., 5, 025204, https://doi.org/1748-9326/5/2/025204, 2010.

Lowry, R.: Concepts and applications of inferential statistics, available at: http://vassarstats.net/textbook/ (last access: 20 June 2019), 2014.

Moorthy, K. K., Beegum, S. N., Srivastava, N., Satheesh, S., Chin, M., Blond, N., Babu, S. S., and Singh, S.: Performance evaluation of chemistry transport models over India, Atmos. Environ., 71, 210-225, https://doi.org/10.1016/j.atmosenv.2013.01.056, 2013.

Nair, V. S., Solmon, F., Giorgi, F., Mariotti, L., Babu, S. S., and Moorthy, K. K.: Simulation of South Asian aerosols for regional climate studies, J. Geophys. Res.-Atmos., 117, D04209, https://doi.org/10.1029/2011JD016711, 2012.

Nair, V. S., Babu, S. S., Moorthy, K. K., Sharma, A. K., Marinoni, A., and Ajai: Black carbon aerosols over the Himalayas: direct and surface albedo forcing, Tellus B, 65, 19738, https://doi.org/10.3402/tellusb.v65i0.19738, 2013.

Pan, X., Chin, M., Gautam, R., Bian, H., Kim, D., Colarco, P. R., Diehl, T. L., Takemura, T., Pozzoli, L., Tsigaridis, K., Bauer, S., and Bellouin, N.: A multi-model evaluation of aerosols over South Asia: common problems and possible causes, Atmos. Chem. Phys., 15, 5903-5928, https://doi.org/10.5194/acp15-5903-2015, 2015.

Peng, J., Hu, M., Guo, S., Du, Z., Zheng, J., Shang, D., Levy Zamora, M., Zeng, L., Shao, M., Wu, Y.-S., Zheng, J., Wang, Y., Glen, C. R., Collins, D. R., Molina, M. J., and Zhang, R.: Markedly enhanced absorption and direct radiative forcing of black carbon under polluted urban en- vironments, P. Natl. Acad. Sci. USA, 113, 4266-4271, https://doi.org/10.1073/pnas.1602310113, 2016.

Ramanathan, V., Crutzen, P. J., Lelieveld, J., Mitra, A. P., A1thausen, D., Anderson, J., Andreae, M. O., Cantrell, W., Cass, G. R., Chung, C. E., Clarke, A. D., Coakley, J. A., Collins, W. D., Conant, W. C., Dulac, F., Heintzenberg, J., Heymsfield, A. J., Holben, B., Howell, S., Hudson, J., Jayaraman, A., Kiehl, J. T., Krishnamurti, T. N., Lubin, D., McFarquhar, G., Novakov, T., Ogren, J. A., Podgorny, I. A., Prather, K., Priestley, K., Prospero, J. M., Quinn, P. K., Rajeev, K., Rasch, P., Rupert, S., Sadourny, R., Satheesh, S. K., Shaw, G. E., Sheridan, P., and Valero, F. P. J.: Indian Ocean Experiment: An integrated analysis of the climate forcing and effects of the great Indo-Asian haze, J. Geophys. Res.-Atmos., 106, 28371-28398, https://doi.org/10.1029/2001JD900133, 2001.

Ramanathan, V., Chung, C., Kim, D., Bettge, T., Buja, L., Kiehl, J., Washington, W., Fu, Q., Sikka, D., and Wild, M.: Atmospheric brown clouds: Impacts on South Asian climate and hydrological cycle, P. Natl. Acad. Sci. USA, 102, 5326-5333, https://doi.org/10.1073/pnas.0500656102, 2005.

Reddy, M. S., Boucher, O., Venkataraman, C., Verma, S., Léon, J.F., Bellouin, N., and Pham, M.: General circulation model estimates of aerosol transport and radiative forcing during the Indian Ocean Experiment, J. Geophys. Res.-Atmos., 109, D16205, https://doi.org/10.1029/2004JD004557, 2004.

Satheesh, S. K., Ramanathan, V., Li-Jones, X., Lobert, J. M., Podgorny, I. A., Prospero, J. M., Holben, B. N., and Loeb, N. G.: A model for the natural and anthropogenic aerosols over the tropical Indian Ocean derived from Indian Ocean Experiment data, J. Geophys. Res.-Atmos., 104, 27421-27440, https://doi.org/10.1029/1999JD900478, 1999.

Shiraiwa, M., Selzle, K., and Pöschl, U.: Hazardous components and health effects of atmospheric aerosol particles: reactive oxygen species, soot, polycyclic aromatic compounds and allergenic proteins, Free Radical Res., 46, 927-939, https://doi.org/10.3109/10715762.2012.663084, 2012.

Sivacoumar, R., Bhanarkar, A., Goyal, S., Gadkari, S., and Aggarwal, A.: Air pollution modeling for an industrial complex and model performance evaluation, Environ. Pollut., 111, 471-477, https://doi.org/10.1016/S0269-7491(00)00083-X, 2001.

Srivastava, A. K., Tiwari, S., Devara, P. C. S., Bisht, D. S., Srivastava, M. K., Tripathi, S. N., Goloub, P., and Holben, B. N.: Premonsoon aerosol characteristics over the Indo-Gangetic Basin: implications to climatic impact, Ann. Geophys., 29, 789-804, https://doi.org/10.5194/angeo-29-789-2011, 2011.

Stull, R. B.: An introduction to boundary layer meteorology, vol. 13, Springer Science \& Business Media, 2012.

Valavanidis, A., Fiotakis, K., and Vlachogianni, T.: Airborne Particulate Matter and Human Health: Toxicological Assessment and Importance of Size and Composition of Particles for Oxidative Damage and Carcinogenic Mechanisms, J. Environ. Sci. Heal. C, 26, 339-362, https://doi.org/10.1080/10590500802494538, 2008.

Vinoj, V., Rasch, P. J., Wang, H., Yoon, J.-H., Ma, P.-L., Landu, K., and Singh, B.: Short-term modulation of Indian summer monsoon rainfall by West Asian dust, Nat. Geosci., 7, 308-313, https://doi.org/10.1038/ngeo2107, 2014.

Wang, Y., Zhang, R., and Saravanan, R.: Asian pollution climatically modulates mid-latitude cyclones following hierarchical 
modelling and observational analysis, Nat. Commun., 5, 3098, https://doi.org/10.1038/ncomms4098, 2014.

Yasunari, T. J., Bonasoni, P., Laj, P., Fujita, K., Vuillermoz, E., Marinoni, A., Cristofanelli, P., Duchi, R., Tartari, G., and Lau, K.-M.: Estimated impact of black carbon deposition during premonsoon season from Nepal Climate Observatory - Pyramid data and snow albedo changes over Himalayan glaciers, Atmos. Chem. Phys., 10, 6603-6615, https://doi.org/10.5194/acp10-6603-2010, 2010. 